\title{
Hydrophobization, smoothing and barrier improvements of cellulose nanofibril films by sol-gel coatings
}

Vartiainen, Jari ; Rose, Klaus ; Kusano, Yukihiro; Mannila, Juha ; Wikström, Lisa

Published in:

Journal of Coatings Technology and Research

Link to article, DOI:

$10.1007 / \mathrm{s} 11998-019-00292-5$

Publication date:

2019

Document Version

Peer reviewed version

Link back to DTU Orbit

Citation (APA):

Vartiainen, J., Rose, K., Kusano, Y., Mannila, J., \& Wikström, L. (2019). Hydrophobization, smoothing and barrier improvements of cellulose nanofibril films by sol-gel coatings. Journal of Coatings Technology and Research. https://doi.org/10.1007/s11998-019-00292-5

\section{General rights}

Copyright and moral rights for the publications made accessible in the public portal are retained by the authors and/or other copyright owners and it is a condition of accessing publications that users recognise and abide by the legal requirements associated with these rights.

- Users may download and print one copy of any publication from the public portal for the purpose of private study or research.

- You may not further distribute the material or use it for any profit-making activity or commercial gain

- You may freely distribute the URL identifying the publication in the public portal 


\title{
Hydrophobization, smoothing and barrier improvements of cellulose nanofibril films by sol-gel coatings
}

\author{
Jari Vartiainen ${ }^{1}$, Klaus Rose ${ }^{2}$, Yukihiro Kusano ${ }^{3}$, Juha Mannila ${ }^{4}$ and Lisa Wikström ${ }^{4}$. \\ ${ }^{1}$ VTT Technical Research Centre of Finland Ltd. Biologinkuja 7, Espoo, FI-02044 VTT, Finland \\ ${ }^{2}$ Fraunhofer-Institut Silicatforschung, Neunerplatz 2, D-97082 Wuerzburg, Germany \\ ${ }^{3}$ Technical University of Denmark, Risø Campus, DK-4000 Roskilde, Denmark, yuki@dtu.dk \\ ${ }^{4}$ VTT Technical Research Centre of Finland Ltd. Visiokatu 4, Tampere, FI-33720 Tampere, Finland
}

\begin{abstract}
Single layer films from cellulose nanofibrils on a plastic support were coated with sol-gel coated with inorganic-organic copolymers (ORMOCER ${ }^{\circledR} \mathrm{S}$ ), consisting of inorganic Si-O-Si based networks combined with ceramic (Al-O- and $\mathrm{Zr}-\mathrm{O}-$ ) groups and special organic fluoroalkyl chain containing functional groups. Sol-gel coatings decreased the surface hydrophilicity and water vapor transmission rate. The water contact angle of uncoated films was $24^{\circ}$, indicating high affinity between water and the cellulose nanofibrils. All sol-gel coatings tested increased the surface hydrophobicity with the contact angles ranging between 54 and $102^{\circ}$. The water vapor transmission rates were varying between 230 and $410 \mathrm{~g} / \mathrm{m}^{2} /$ day. With UV curable highly organically crosslinked coating, the water vapor transmission rate was decreased by $77 \%$ as compared to uncoated film. The uncoated film had oxygen transmission rates of 0.7 and 107 $\mathrm{cc} / \mathrm{m}^{2} /$ day at $50 \%$ and $80 \% \mathrm{RH}$, respectively. At high humidity conditions, the films tend to swell thus allowing permeation to increase. Sol-gel coatings significantly improved the oxygen barrier properties especially at $80 \% \mathrm{RH}$. The transmission rates were varying between 0.4 and 0.5 $\mathrm{cc} / \mathrm{m}^{2} /$ day $(50 \% \mathrm{RH})$ and between 51 and $86 \mathrm{cc} / \mathrm{m}^{2} /$ day $(80 \% \mathrm{RH})$.
\end{abstract}

Keywords: cellulose nanofibrils, sol-gel, film, coating

\section{Introduction}

Bioeconomy, also referred to as green economy aims for sustainable development with decreased environmental impact. The bioeconomy should be based less on fossil raw materials and more on biomass-derived renewable resources. Replacing the fossil-based films in packaging, transportation and printing industry with bio-based materials might give an advantage due to not only more sustainable image, but also improved properties. Current trends in the packaging and transport industry are towards lighter weight materials for reduction of raw material use, transportation costs, and the amount of waste [1]. Biopolymers such as cellulose, pectin, xylan, starch or chitosan are considered to be environmentally sustainable alternatives for synthetic packaging materials [2]. For example, cellulose nanofibrils (CNFs) are among the most promising innovations especially due to its excellent oxygen and mineral oil barrier properties [3-5]. However, the moisture resistance of most sustainable biopolymers is still insufficient, thus moisture absorption and excessive water vapor permeation through packaging degrades the 
quality of food and other goods, resulting in short shelf-lives, increased costs and more waste [6]. Several approaches have been attempted for improving the moisture tolerance of CNF films. In spite of the efforts made by surface silylation [7-8], paraffin wax [3], aluminium oxide $\left(\mathrm{Al}_{2} \mathrm{O}_{3}\right)$ [9], alkyl ketene dimer (AKD) [10] and cellulose fatty acid ester coatings [11], or grafting with hydrophobic dodecyl gallate [12], crosslinking [13], compounding with nanoclays [14] or impregnation with walnut oil [15], there is still a need for a more powerful method for hydrophobization of CNF films in a cost effective way. Meanwhile the markets for printed electronics, organic photovoltaics and biosensors are rapidly growing. The research activities on sustainable and environmentally sound raw materials especially in printed electronics have increased globally due to remarkable population growth together with limited biophysical resources. The CNF films are potentially utilized in certain printed electronics applications [16-19]. The requirements for surface smoothness and dimensional stability at high humidity, however, are demanding in most of these applications so that the traditional CNF films cannot fulfil them sufficiently. The surface roughness, which is more or less a natural feature of any surface formed from imperfect dispersions, may be overcome by using additional coatings with low porosity. As monolayer biopolymer films rarely have competitive edge against synthetic films, the coated structures are necessary. By multilayer structures the barrier properties and smoothness of biobased materials may be dramatically improved.

Impregnating, hydrophobizing, oleophobizing and barrier agents commonly used are typically applied by a simple coating method. While substances with long alkyl chains are often sufficient for water repellent effects (hydrophobicity), fluorinated alkyl chains are usually necessary to achieve oil and fat repellency (oleophobicity) as well as water repellency. Moreover, for establishing desirable barrier properties, a highly densified network or a high degree of crosslinking in the coating material is an essential prerequisite. Sol-gel processing with the relevant alkoxysilyl or alkoxy metal compounds is a well-established method to build up these elements in a solution. Finally, wet coatings containing these elements can be processed by known wet chemical techniques and will be cured at moderate temperatures or by using UV light to initiate the organic polymerization of incorporated reactive groups. The basic technology, which was also used for coatings in the present study, is schematically illustrated in Figure 1.

The resulting materials exhibit properties between inorganic and organic polymers. Owing to the wide range of possible combinations and variations of inorganic and organic components, these materials can be used in many applications, for example, in wear resistant coatings for plastics [20], functional coatings on glass [21], sensor coatings for gas detection [22], corrosion protection layers for metals [23], coatings for microelectronic devices [24] and anti-static and easy-to-clean coatings [25].

In the present work, CNF coated plastic supports were further coated with sol-gel coatings and coating characteristics and barrier performances were examined. The overall goal is to develop an economically viable production method for lightweight structures based on sustainable materials with added value properties. 

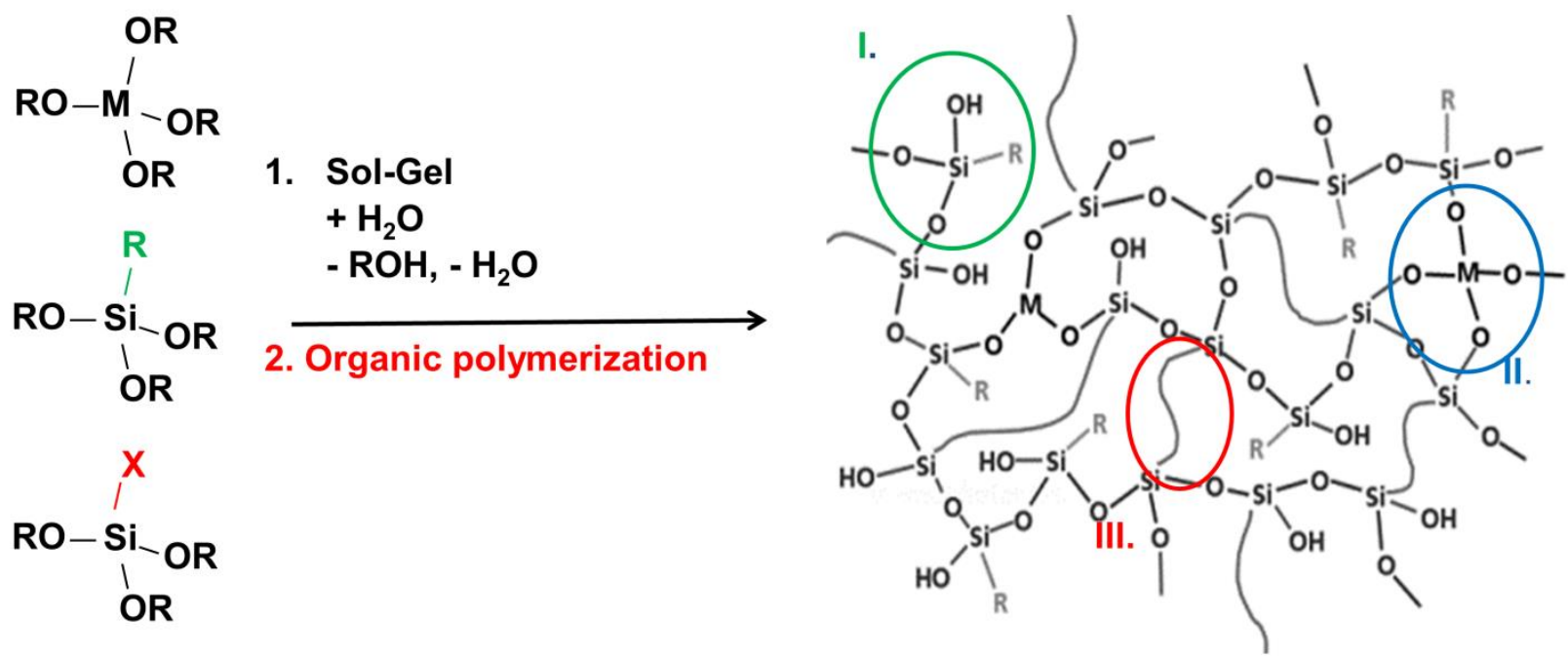<smiles></smiles>

I: organically-functionalized siloxane $\Rightarrow$ film formation, adhesion, polarity, conductivity, surface energy, flexibility

II: inorganic oxides

III: organic polymer chains
=> mechanical, thermal, chemical stability, rigidity

$\Rightarrow$ film curing, flexibility, cross-linking

Figure 1. Synthesis of inorganic organic hybrid ORMOCER ${ }^{\circledR}$ coating materials via sol-gel process and their features.

\section{Materials \& Methods}

\section{Cellulose nanofibrils (CNF) and CNF films}

A native never dried birch kraft pulp was used to produce CNF. Mechanical disintegration was carried out with a fluidizer to obtain a fibre slurry. It was immersed in water at $1.7 \%$ consistency and dispersed using a Diaf dissolver $100 \mathrm{WH}$ (Denmark), at $700 \mathrm{rpm}$ for 10 minutes. Prerefinement of the suspension was performed three times in a grinder (Supermasscolloider MKZA10-15J, Masuko Sangyo Co., Japan) at $1500 \mathrm{rpm}$. The pre-refined fibre suspension was fibrillated further in a Microfluidics fluidizer M-7115-30 (USA) three times at a pressure of 1800 bar. The appearance of the final fibre slurry was a viscous and translucent gel with a solid content of $1.91 \%, \mathrm{pH} 7.26$, electrical conductivity of $195 \mu \mathrm{S} / \mathrm{cm}$ and the residual fibre amount of 39 $\mathrm{pcs} / \mathrm{mg}$. Rheological characteristics of the fibre slurry were analysed with a rheometer Anton Paar MCR301 with ST22-4V vane spindle at $0.5 \%$ consistency. The fibre slurry exhibited a storage modulus of $6.76 \mathrm{~Pa}$, a loss modulus of $0.87 \mathrm{~Pa}$ and an apparent viscosity of $241 \mathrm{mPa}$ s at $600 \mathrm{rpm}$.

A patented SutCo-concept [26] was employed to produce CNF films. The dispersion included $30 \%$ of sorbitol (D-sorbitol, Sigma-Aldrich). It was first homogenized by mixing with Diaf dissolver (100 WH, Denmark) for $30 \mathrm{~min}$ at $300 \mathrm{rpm}$ and then with SpeedMixer (DAC 110.1 VAC-p, Hauschild) for $2 \mathrm{~min}$ at $1500 \mathrm{rpm}$ at a reduced pressure to prevent formation of gas bubbles. After that it was cast onto a plastic support using a specific feeding head. At the feeding head the dispersion 
formed an even and uniform wet layer. Spreading and adhesion between the support and the dispersion were controlled by plasma treatment. Vetaphone Corona-Plus (Type TF-415, CP1C MKII $2.0 \mathrm{~kW}$, Denmark) equipped with argon/nitrogen plasma-unit was used for increasing the surface energy of the plastic support. After drying overnight at ambient conditions, dry CNF films with thickness of $37 \pm 1 \mu \mathrm{m}$ were delaminated from the plastic support and cut into A4-sized sheets.

\section{Sol-gel coatings}

In the present study, inorganic-organic copolymers (ORMOCER ${ }^{\circledR} \mathrm{s}$ ) were used for combining the above properties with suitable coating materials for CNF films. Essential components of these types of materials are the inorganic Si-O-Si based networks which can be combined with ceramic (such as Al-O-, Ti-O- or Zr-O-) and specific organic fluoroalkyl chain containing functional groups. The former will contribute to the high density of the resulting material exhibiting especially the barrier properties and the latter will be responsible for specific surface properties such as oleophobicity and hydrophobicity.

The chemical compositions of the selected coatings described in the present study are summarized in Figure 2. Table 1 summarizes detailed information of the sol-gel coatings. The components are presented after hydrolysis and condensation reactions as they are incorporated in the inorganic basic network. Wet coatings were applied onto the CNF films by a doctor blade applicator. UV curing was performed by using a mercury lamp for $20 \mathrm{~s}$ with approximately 5000 $\mathrm{mJ} / \mathrm{m}^{2}$. Thermal curing was performed at $130^{\circ} \mathrm{C}$ for $1 \mathrm{~h}$.

\section{Scanning electron microscopy (SEM)}

Sol-gel coated films were embedded in an epoxy resin, grinded and polished for the micro- and nano-structural observation. In addition, surfaces of the films were observed without embedding them in the epoxy resin. Before observation, an approximately 15-nm thick gold coating was sputter-deposited on the sample surface for avoiding charging-up due to electron irradiation. Field emission scanning electron microscopy (FE-SEM. SUPRA 35, Zeiss, Germany) was used for the observation.

\section{Roughness}

Wyko NT9100 Optical Profiling System determined the micro-roughness average (Ra) of the films. $\mathrm{Ra}$ is the arithmetic mean of the absolute values of the surface departures from the mean plane. It is a stable, easily implemented parameter, useful for detecting general variations in overall surface height characteristics. Magnification of $10.1 \times$, mode: VSI and $1000 \mu \mathrm{m} \times 1000 \mu \mathrm{m}$ scan area was used.

\section{Gloss}

Gloss of the coated surface was measured using a laboratory glossmeter (Zehntner, ZLR 1050, Hoelstein, Switzerland). Reflectance was measured at an incidence light angle of $75^{\circ}$ from the normal to the sample surface. Gloss was reported as gloss units (GU). 


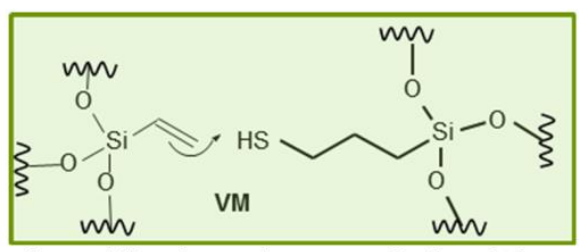

VMc: UV curable, highly densified and crosslinked inorganic and organic network
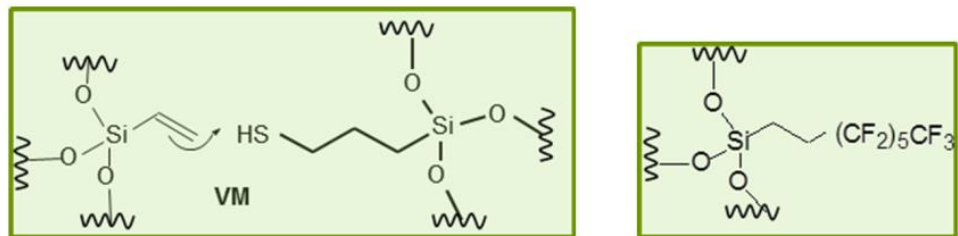

VMc F: UV curable, highly densified and crosslinked inorganic and organic network, combined with an oleophobic fluoroalkyl chain

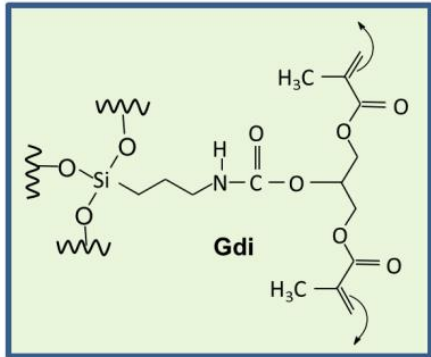

Gdi: UV curable highly organically crosslinked structure
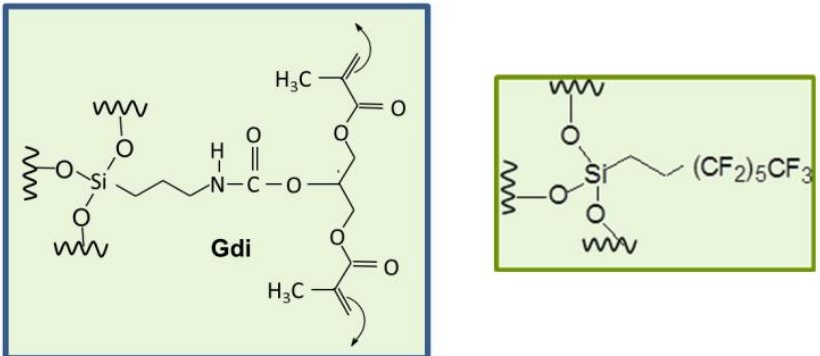

Gdi F: UV curable highly organically crosslinked structure, combined with an oleophobic fluoroalkyl chain

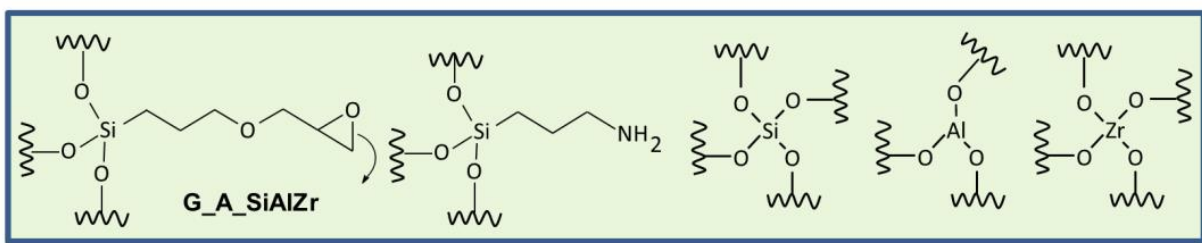

G_A_SiAIZr: Thermally curable system based on highly densified inorganic $\mathrm{Si-O/AI-O/Zr-O}$ oxidic network

Figure 2. Chemical compositions of the sol-gel coatings. $m w$ represents the inorganic network, and $\sim$ represents the organic polymerization. 
Table 1. Composition formulae, names of components, and molar ratios.

\begin{tabular}{|c|c|c|}
\hline Composition formula & Name of functional components & Molar ratio \\
\hline VMc & $\begin{array}{l}\text { Vinylsilane „V“ } \\
\text { Mercaptopropylsilane „Mc“ }\end{array}$ & $\begin{array}{l}50 \\
50\end{array}$ \\
\hline VMc_F & $\begin{array}{l}\text { Vinylsilane „V“ } \\
\text { Mercaptopropylsilane „Mc" } \\
\text { Fluoroalkylsilane „F“ }\end{array}$ & $\begin{array}{c}48,5 \\
48,5 \\
3\end{array}$ \\
\hline Gdi & Glyceryldimethacrylate silane „Gdi“ & 100 \\
\hline Gdi_F & $\begin{array}{l}\text { Glyceryldimethacrylate silane „Gdi“ } \\
\text { Fluoroalkyl silane „F“ }\end{array}$ & $\begin{array}{c}97 \\
3\end{array}$ \\
\hline G_A_SiAlZr & $\begin{array}{l}\text { Glycidoxypropylsilane „G“ } \\
\text { Aminosilane „A“ } \\
\text { Peralkoxylated silane „Si" } \\
\text { Peralkoxylated aluminium „Al" } \\
\text { Peralkoxylated zirconium „Zr" }\end{array}$ & $\begin{array}{c}45 \\
5 \\
30 \\
10 \\
10\end{array}$ \\
\hline
\end{tabular}

\section{Contact angle measurements}

Water contact angles of the films were measured using CAM200 equipment (KSV Instruments, Finland) in test conditions of $23^{\circ} \mathrm{C}$ and $50 \%$ relative humidity (RH). For each measurement, the water sessile drops were placed on the surface of the sample, and images were recorded every second for $1 \mathrm{~min}$. The water contact angle of each sample was measured at 3-5 different positions, and the average value was calculated.

\section{Oxygen permeation}

The standard ASTM D3985 was employed for the measurement of an oxygen transmission rate using Oxygen Permeation Analyser Models 8001 and 8011 (Systech Instruments Ltd, UK). Films of $50 \mathrm{~cm}^{2}$ were tesed at the conditions of at the temperature at $23^{\circ} \mathrm{C}$ and the humidity at $50 \%$ and $80 \% \mathrm{RH}$. The test gas used was $100 \%$ oxygen.

\section{Water vapor permeation}

A water vapor transmission rate of the films was determined gravimetrically using a modified ASTM-E-96B procedure "wet cup method". Samples with a test area of $30 \mathrm{~cm}^{2}$ were mounted on circular aluminum cups (68-3000 Vapometer EZ-Cups; Thwing-Albert Instrument Company) containing distilled water $(100 \% \mathrm{RH})$. The cups were stored in test conditions of $23^{\circ} \mathrm{C}$ and $50 \% \mathrm{RH}$ and weighed periodically until a constant rate of weight reduction was attained. Climaveneta climate control system (Italy) model AXO 10 controlled both temperature and humidity conditions in an environmental chamber. Humidity gradient is the driving force for water molecules to diffuse within a material. In this test, $100 / 50 \%$ RH gradient was used. 


\section{Results \& Discussion}

CNF films consist of networks of individual or bundled CNFs. High pressure homogenization was used to separate the individual CNFs. Feed solutions were pumped from the inlet reservoir and pressurized by an intensifier pump to high pressure of 1800 bar and fed three times through fixed geometry chambers. Within the chambers the high pressures forced fibril networks to form turbulent and opposing jets, which contributed to mixing in nanometer scale, minimizing diffusion limitation. A diameter of single CNFs is typically a few nanometers whereas the lengths may be up to several micrometers. Between the junction points of the fibril network, some open voids and porosity may exist. Additional fibrillation leads into a finer fibril structure which improves the surface smoothness of the films. SEM images at the surfaces and the cross-sections of the sol-gel coated CNF films are shown in Fig. 3. As can be seen, the surface nano-roughness of the uncoated CNF film was considerably higher than those of all coated films. The individual CNFs on the surface were well-covered with the relatively dense and homogeneous coating layers. The nanoscale morphologies of the coatings, however, slightly differentiated from each other. Based on the cross-sectional images the layer thickness of the coatings and the CNF films were 2-4 $\mu \mathrm{m}$ and 22$27 \mu \mathrm{m}$, respectively. They are based on localized observations and it is difficult to define representative thickness values, especially when the observed values are significantly varied. Therefore, data analysis per thickness was not attempted. The adhesion between the coatings and the support was generally good. The cracks consistently appeared in the cross-sectional images in Fig. 3 were most likely created during the preparation of the epoxy embedded samples due to shrinkage of the epoxy during curing. 

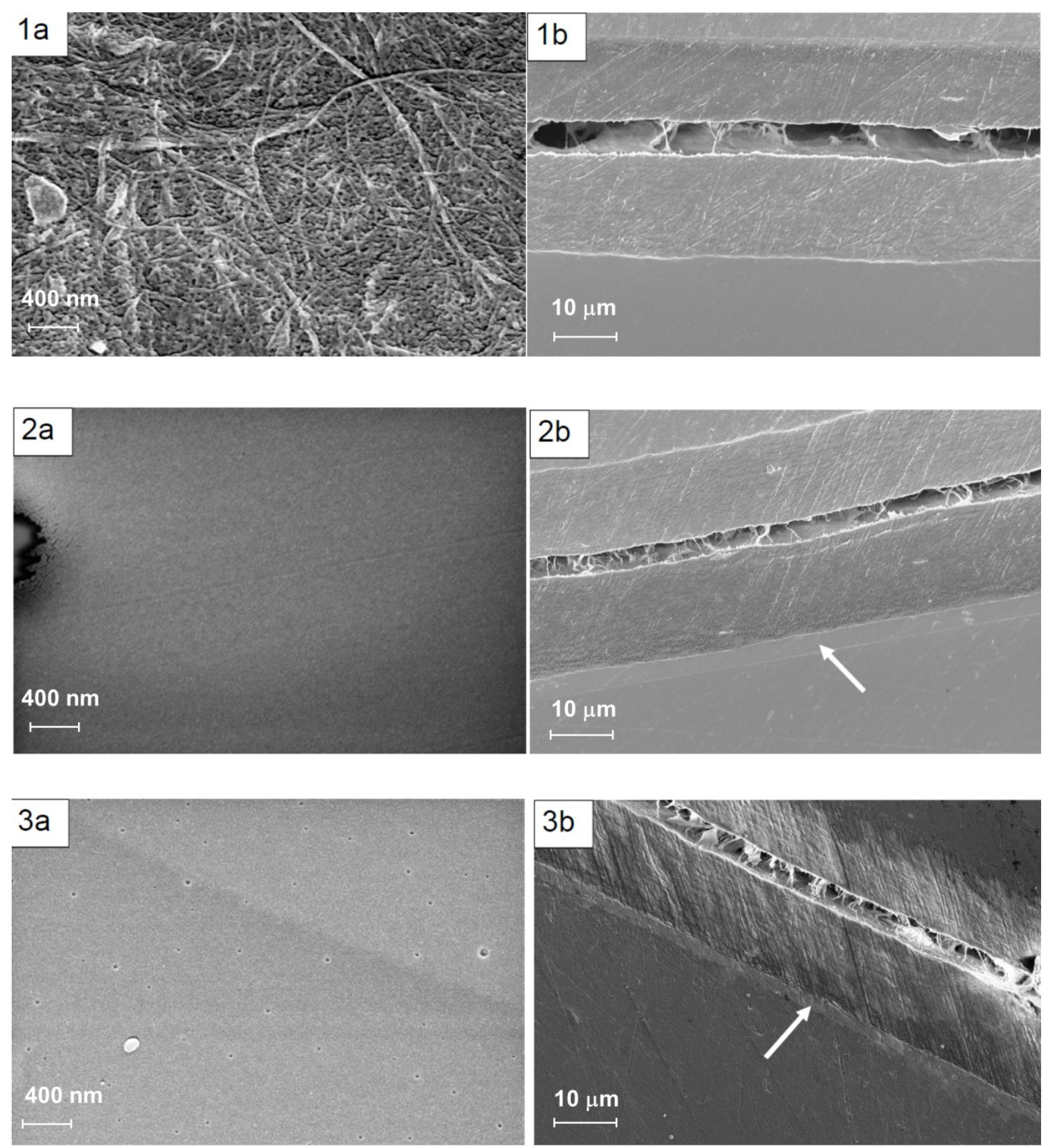

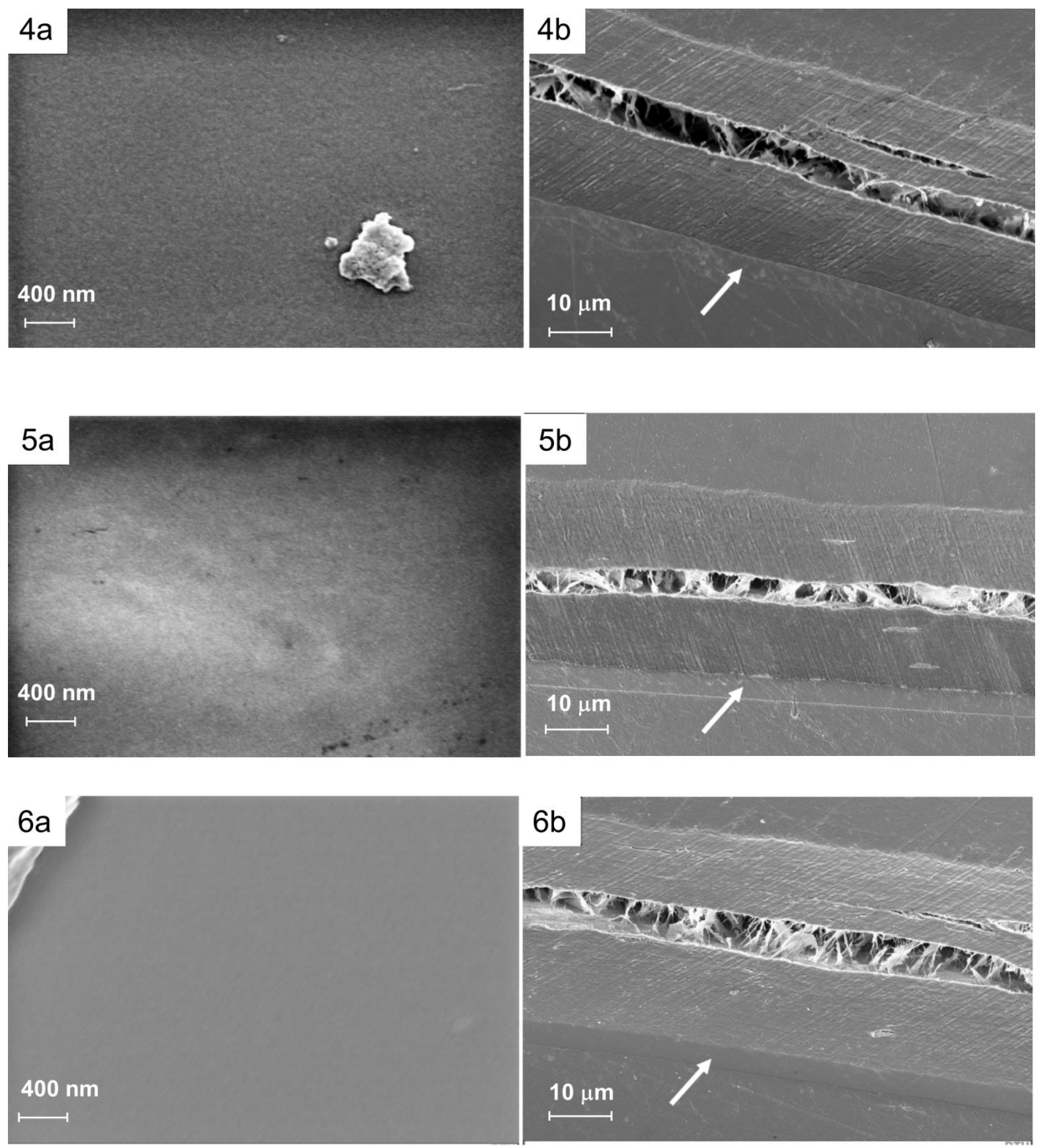

Figure 3. Scanning electron microscopic images of the surface topography (a) and cross-section (b) of the sol-gel coated CNF films as follows: (1) no coating, (2) VMc, (3) VMc F, (4) Gdi, (5) Gdi F and (6) G_A_SiAlZr. The sol-gel coatings are marked with an arrow. 

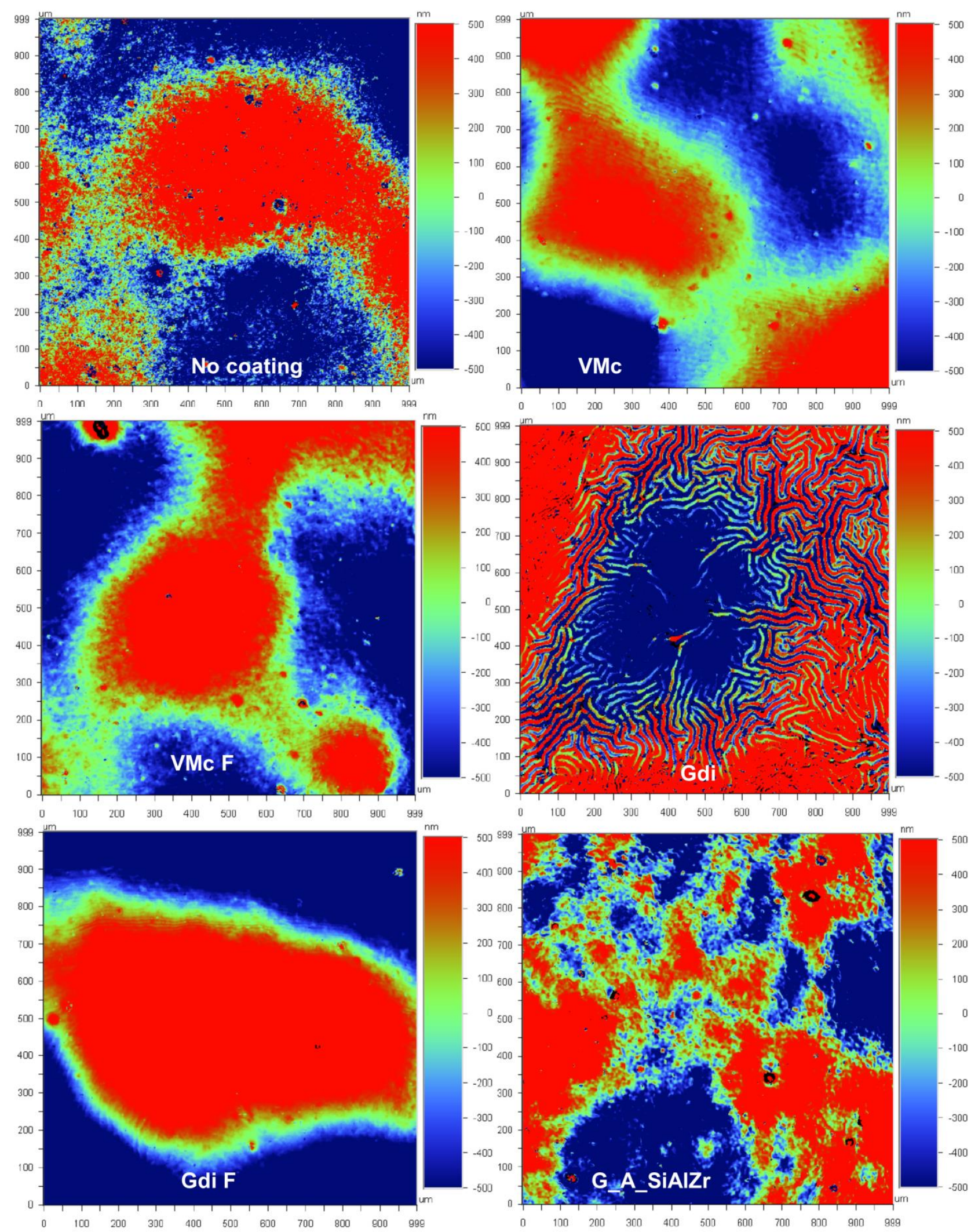

Figure 4. Surface topography of the sol-gel coated CNF films measured with Wyko NT9100 Optical Profiling System. Magnification of $10.1 \times$, mode: VSI and $1000 \mu \mathrm{m} \times 1000 \mu \mathrm{m}$ scan area was used. 
Table 2. Water contact angle, gloss and roughness of the sol-gel coated CNF films.

\begin{tabular}{|l|c|c|c|c|}
\hline Coating & $\begin{array}{c}\text { Coating grammage } \\
\left(\mathrm{g} / \mathrm{m}^{2}\right)\end{array}$ & $\begin{array}{c}\text { Water contact angle } \\
\text { after } 30 \mathrm{sec} .\left(^{\circ}\right)\end{array}$ & $\begin{array}{c}\text { Gloss } 75^{\circ} \\
(\mathrm{GU})\end{array}$ & $\begin{array}{c}\text { Roughness average } \mathrm{R}_{\mathrm{a}} \\
(\mathrm{nm})\end{array}$ \\
\hline no coating & - & 24 & 79.2 & 621 \\
\hline VMc & 5.6 & 71 & 104.0 & 353 \\
\hline VMc F & 3.5 & 102 & 102.1 & 431 \\
\hline Gdi & 6.2 & 71 & 29.8 & 1010 \\
\hline Gdi F & 1.9 & 99 & 98.7 & 813 \\
\hline G_A_SiAlZr & 7.6 & 54 & 92.4 & 496 \\
\hline
\end{tabular}

Surface topography of the sol-gel coated CNF films is shown I Fig. 4, measured with Wyko NT9100 Optical Profiling System. Regarding the micro-roughness, the results were somewhat different. Based on the optical profilometry, the surface smoothness was clearly improved only with VMc, VMc F and G_A_SiAIZr coatings. Especially the inorganic/organic networks also efficiently increased the gloss-value. Gdi was suffering from both high micro-roughness (Fig. $4 \mathrm{Gdi}$ ) and low gloss-value probably (Table 2 ) due to unsuitable drying conditions.

A variation of the measured coating grammage in Table 2 can be associated with wetting characteristics of the coatings applied on to the CNF films. When fluorine is included in the coatings such as VMc F and Gdi F, the coating grammage tends to be lower probably due to a mismatch of the surface tensions between the fluorine containing coating materials and the CNF film surfaces. However, the coating grammage of Gdi F $\left(1,9 \mathrm{~g} \mathrm{~m}^{-2}\right)$ seems too low, since the density of the Gdi F coating would be lower than $1 \mathrm{~g} \mathrm{~cm}^{-3}$. It may be due to macroscopic unevenness of the Gdi F coating.

High density of hydroxyl groups on the CNF film surface results in increased hydrophilic behavior which can be measured with water contact angle measurements. The water contact angle of unmodified CNF surface was $24^{\circ}$, indicating very high affinity between water and the surface (Table 2). All sol-gel coatings clearly increased the surface hydrophobicity with the contact angles varying between $54^{\circ}$ and $102^{\circ}$. Oleophobic fluoroalkyl chains improved the hydrophobicity of both VMc and Gdi coatings. A thermally curable coating from an inorganic Si-O/Al-O/Zr-O oxidic network only slightly increased the water contact angle. Overall, the hydrophobic effects on CNF films were comparable to plasma silylation and walnut oil impregnation $[8,15]$.

Oxygen and water vapor transmission rates of the sol-gel coated CNF films are summarized in Table 3. CNF films are typically excellent barriers against oxygen permeation. The uncoated CNF film had oxygen transmission rates of 0.7 and $107 \mathrm{cc} / \mathrm{m}^{2} /$ day at $50 \%$ and $80 \% \mathrm{RH}$, respectively (Table 3). The results were comparable to regenerated cellulose films and other studies of CNF at elevated humidity $[6,10,27-33]$. During drying the CNFs are closely packed which reduced the free volume and efficiently prevented the oxygen permeation. Large surface area and high polarity of nano-sized fibrils resulted in enhanced fibril-to-fibril attraction especially at lower humidity. Due to the hydrogen bonds the movement of fibrils was restricted efficiently preventing the oxygen permeation. The barrier properties of cellulosic films are sensitive to moisture variations. Water molecules diffuse into the structure and break the hydrogen bonds that hold the chains together. At high humidity conditions, the CNF films tend to swell, increasing permeation. Sol-gel coatings 
efficiently improved the oxygen barrier properties especially at $80 \% \mathrm{RH}$. The transmission rates were varying between 0.4 and $0.5 \mathrm{cc} / \mathrm{m}^{2} /$ day $(50 \% \mathrm{RH})$ and between 51 and $86 \mathrm{cc} / \mathrm{m}^{2} /$ day $(80 \%$ $\mathrm{RH})$, respectively. By using G_A_SiAIZr coating, the oxygen transmission rate was decreased by $52 \%$ at $80 \% \mathrm{RH}$ as compared to uncoated CNF film. Water vapor transmission rates through cellulosic films are typically high due to strong hydrophilic nature of these materials. The penetrating water molecules break intramolecular hydrogen bonds which enables plasticization and swelling of the matrix polymer finally resulting in increased moisture permeation. Water vapor transmission rates of uncoated CNF films were comparable to previously reported bleached softwood and hardwood CNF films [6] and regenerated cellulose and chitosan films [10,34]. Sol-gel coatings efficiently decreased the moisture permeability. The water vapor transmission rates were varying between 230 and $410 \mathrm{~g} / \mathrm{m} 2 /$ day and with Gdi coating, the transmission rate was decreased by $77 \%$ as compared to uncoated CNF film. The water vapor transmission rates were lower than with cellulose fatty acid ester coated, plasma silylated or walnut oil impregnated CNF films $[8,11,15]$, but not as good as with beeswax and paraffin wax coated microfibrillated cellulose (MFC) films [35], alkyd resin/CNF coated kraft paper [36] or shellac/MFC coated paperboard [37].

Table 3. Oxygen and water vapor transmission rates of the sol-gel coated CNF films.

\begin{tabular}{|l|c|c|c|}
\hline Coating & $\begin{array}{c}\text { OTR at } 23^{\circ} \mathrm{C}, \\
50 \% \mathrm{RH} \\
\left(\mathrm{cc} / \mathrm{m}^{2} / \text { day) }\right.\end{array}$ & $\begin{array}{c}\text { OTR at } 23^{\circ} \mathrm{C}, \\
80 \% \mathrm{RH} \\
\left(\mathrm{cc} / \mathrm{m}^{2} / \text { day }\right)\end{array}$ & $\begin{array}{c}\text { WVTR at } 23^{\circ} \mathrm{C}, \\
100 / 50 \% \mathrm{RH} \\
\left(\mathrm{g} / \mathrm{m}^{2} / \text { day }\right)\end{array}$ \\
\hline no coating & 0.7 & 107 & 990 \\
\hline VMc & 0.5 & 74 & 240 \\
\hline VMc F & 0.5 & 86 & 370 \\
\hline Gdi & 0.4 & 78 & 230 \\
\hline Gdi F & 0.5 & 77 & 260 \\
\hline G_A_SiAIZr & 0.5 & 51 & 410 \\
\hline
\end{tabular}

\section{Conclusion}

Sol-gel coated CNF films were prepared to examine coating properties and oxygen and water permeability. Sol-gel coatings exhibited relatively dense and homogeneous coating layers with sufficiently strong adhesion to the CNF coatings, and improved the technical performance of the CNF films. Especially the moisture resistance and surface hydrophobicity were improved due to inorganic-organic copolymer coatings (ORMOCER ${ }^{\circledR}$ s). The results of this study will contribute to the development of the techno-economically feasible production methods for lightweight structures based on sustainable materials with added value properties.

\section{Acknowledgements}

This work was supported by the European Union Seventh Framework Programme (FP7/20072013) with a grant number NMP2013-10-608746. Anette Pedersen is acknowledged for preparation of the SEM specimens. 


\section{References}

[1] Johansson, C, Bras, J, Mondragon, I, Nechita, P, Plackett, D, Simon, P, Gregor Svetec, D, Virtanen, S, Giacinti Baschetti, M, Breen, C, Clegg, F, Aucejo, S, "Renewable Fibers and Bio-Based Materials for Packaging Applications-A Review of Recent Developments." BioResources 7 25062552 (2012)

[2] Khwaldia, K, Arab-Tehrany, E, Desobry, S, "Biopolymer Coatings on Paper Packaging Materials, Comprehensive Reviews in Food Science and Food Safety." 9 82-91 (2010)

[3] Österberg, M, Vartiainen, J, Lucenius, J, Hippi, U, Seppälä, J, Serimaa, R, Laine, J, "A fast method to produce strong NFC films as a platform for barrier and functional materials." ACS Appl. Mater. Interf. Am. Chem. Soc. 5(11) 4640-4647 (2013)

[4] Tammelin, T, Vartiainen, J, "Nanocellulose Films and Barriers. In: Handbook of Green Materials. Processing Technologies, Properties and Applications." Oksman, K, Mathew, AP, Bismarck, A, Rojas, O, Sain, M, (eds.). World Scientific Publishing (2014)

[5] Vartiainen, J, Laine, C, Willberg-Keyriläinen, P, Pitkänen, M, Ohra-aho, T, "Biobased mineral-oil barrier-coated food-packaging films." J. Appl. Polym. Sci. 13444586 (2017)

[6] Vartiainen, J, Vähä-Nissi, M, Harlin, A, "Biopolymer Films and Coatings in Packaging Applications: A Review of Recent Developments." Mater. Sci. Appl. 5(10) 708-718 (2014)

[7] Chinga-Carrasco, G, Kuznetsova, N, Garaeva, M, Galiullina, G, Kostochko, A, Leirset, I, Syverud, $\mathrm{K}$, "Bleached and Unbleached MFC Nanobarriers-Properties and Hydrophobization with Hexamethyldisilazane." J. Nanoparticle Res., 141280 (2012)

[8] Vartiainen, J, Malm, T, "Surface hydrophobization of CNF films by roll-to-roll HMDSO plasma deposition." J. Coat. Technol. Res. 13(6) 1145-1149 (2016)

[9] Hirvikorpi, T, Vähä-Nissi, M, Nikkola, J, Harlin, A, Karppinen, $\mathrm{M}$, “Thin $\mathrm{Al}_{2} \mathrm{O}_{3}$ barrier coatings onto temperature-sensitive packaging materials by atomic layer deposition" Surf. Coat. Technol. 205(21-22) 5088-5092 (2011)

[10] Yang, Q, Saito, T, Isogai, A, “Facile fabrication of transparent cellulose films with high water repellency and gas barrier properties." Cellulose 19 1913-1921 (2012)

[11] Willberg-Keyriläinen, P, Vartiainen, J, Pelto, J, Ropponen, J, "Hydrophobization and smoothing of cellulose nanofibril films by cellulose ester coatings." Carbohydrate Polym. 170 160-165 (2017)

[12] Saastamoinen, P, Mattinen, M, Hippi, U, Nousiainen, P,Sipilä, J, Lille, M, Suurnäkki, A, Pere, J, "Laccase Aided Modification of Nanofibrillated Cellulose with Dodecyl Gallate." BioResources, 7 5749-5770 (2012)

[13] Larsson, P, Pettersson, T, Wågberg, L, “Improved barrier films of cross-linked cellulose nanofibrils: a microscopy study." Green Mater. 2(4) 163-168 (2014)

[14] Spoljaric, S, Salminen, A, Luong, N, Lahtinen, P, Vartiainen, J, Tammelin, T, Seppälä, J, "Nanofibrillated cellulose, poly(vinyl alcohol), montmorillonite clay hybrid nanocomposites with superior barrier and thermomechanical properties." Polym. Compos. 35(6) 1117-1131 (2013) 
[15] Vartiainen, J, Pelto, J, Kaljunen, T, Kenttä, E, "Hydrophobization of cellophane and cellulose nano-fibrils films by supercritical state carbon dioxide impregnation with walnut oil." Nordic Pulp and Paper Res. J. Mid Sweden Univ. 31(4) 541-547 (2016)

[16] Torvinen, K, Sievänen, J, Hjelt, T, Hellén, E, "Smooth and flexible filler-nanocellulose composite structure for printed electronics applications." Cellulose 19(3) 821-829 (2012)

[17] Penttilä, A, Sievänen, J, Torvinen, K, Ojanperä, K, Ketoja, J, "Filler-nanocellulose substrate for printed electronics: experiments and model approach to structure and conductivity." Cellulose 20(3) 1413-1424 (2013)

[18] Torvinen, K, Lehtimäki, S, Keränen, J, Sievänen, J,Vartiainen, J, Hellén, E, Lupo, D, Tuukkanen, $\mathrm{S}$, "Pigment-Cellulose Nanofibril Composite and Its Application as a Separator-Substrate in Printed Supercapacitors." Electronic Mater. Let. 11(6) 1040-1047 (2015)

[19] Mäkelä, T, Kainlauri, M, Willberg-Keyriläinen, P, Tammelin, T, Forsström, U, "Fabrication of micropillars on nanocellulose films using a roll-to-roll nanoimprinting method." Microelectronic Eng. 163 1-6 (2016)

[20] Schottner, G, Rose, K, Posset, U, "Scratch and Abrasion Resistant Coatings on Plastic LensesState of the Art, Current Developments and Perspectives." J. Sol-Gel Sci. Technol. 27 71-79 (2003)

[21] Kron, J, Schottner, G, Deichmann, K-J, "Glass design via hybrid sol-gel materials." Thin Solid Films 392 236-242 (2001)

[22] Matĕjec, M, Rose, K, Hayer, M, Pospisilova, M, Chomat, M, "Development of organically modified polysiloxanes for coating optical fibers and their sensitivity to gases and solvents." Sensors and Actuators B: Chem. 38-39 438-442 (1997)

[23] Greiwe, K, "Korrosionsbeständige Schutzbeschichtung für Messingoberflächen." Farbe \& Lack 97 368-371 (1991)

[24] Popall, M, Kappel, J, Pilz, M, Schulz, J, „A new inorganic-organic polymer for the passivation of thin film capacitors." J. Sol-Gel Sci. Technol. 2 157-160 (1994)

[25] Haas, KH, Amberg-Schwab, S, Rose, K, "Functionalized coating materials based on inorganicorganic polymers." Thin Solid Films 351 198-203 (1999)

[26] Tammelin, T, Salminen, A, Hippi, U, "Method for the preparation of NFC films on supports." Patent WO2013/060934 2013

[27] Newton, K, Rigg, W, "The effect of film permeability on the storage life and microbiology of vacuum packed meat." J. Appl. Bacteriology 47 433-441 (1979)

[28] Wu, J, Yuan, Q, "Gas permeability of a novel cellulose membrane." J. Membrane Sci. 204 185194 (2002)

[29] Aulin, C, Gällstedt, M, Lindström, T, "Oxygen and oil barrier properties of microfibrillated cellulose films and coatings." Cellulose 17(3) 559-574 (2010) 
[30] Plackett, D, Anturi, H, Hedenqvist, M, Ankerfors, M, Gällstedt, M,Lindström, T, Siro, I, "Physical properties and morphology of films prepared from microfibrillated cellulose and microfibrillated cellulose in combination with amylopectin." J. Appl. Polym. Sci. 117 3601-3609 (2012)

[31] Liu, A, Walther, A, Ikkala, O, Belova, L, Berglund, L, "Clay nanopaper with tough cellulose nanofiber matrix for fire retardancy and gas barrier functions." Biomacromolecules 12(3) 633-641 (2011)

[32] Yang, Q, Fukuzumi, H, Saito, T, Isogai, A, Zhang, L, "Transparent cellulose films with high gas barrier properties fabricated from aqueous alkali/urea solutions." Biomacromolecules 12(7) 27662771 (2011)

[33] Wu, C, Saito, T, Fujisawa, S, Fukuzumi, H, Isogai, A, "Ultrastrong and high gas-barrier nanocellulose/clay layered composites." Biomacromolecules 13(6) 1927-1932 (2012)

[34] Vartiainen, J, Tuominen, M, Nättinen, K, "Bio-Hybrid Nanocomposite Coatings from Sonicated Chitosan and Nanoclay." J. Appl. Polym. Sci. 116 3638-3647 (2010)

[35] Spence, K, Venditti, R, Rojas, O, Pawlak, J, Hubbe, M, "Water vapor barrier properties of coated and filled microfibrillated cellulose composite films." BioResources 6(4) 4370-4388 (2011)

[36] Aulin, C, Ström, G, "Multilayered Alkyd Resin/Nanocellulose Coatings for Use in Renewable Packaging Solutions with a High Level of Moisture Resistance." Ind. Eng. Chem. Res. 52 2582-2589 (2013)

[37] Hult, E, lotti, M, Lenes, M, "Efficient approach to high barrier packaging using microfibrillar celluose and shellac." Cellulose 17 575-586 (2010) 